\title{
TATA LETAK GUDANG RAW MATERIAL CHEMICAL MENGGUNAKAN METODE SHARED STORAGE DAN REL SPACE
}

\author{
Indramawan Hadi Kuswoyo, Atikha Sidhi Cahyana \\ Program Studi Teknik Industri \\ Universitas Muhammadiyah Sidoarjo \\ wawan_kuswoyo@yahoo.co.id, atikhasidhi@umsida.ac.id
}

\begin{abstract}
Storage system in the manufacturing industry in this modern era is a very important role especially international scale company, may not directly produce or distribute all of the work unit. this led to the need for raw materials warehouse, warehouse storage systems should not be large in size because if supported by a good inventory of the warehouse to the maximum utilization of the problems faced by the company occurred in the warehouse of raw materials (raw materials). deficiencies in the arrangement of items in the warehouse procedures cause problems in the warehouse, so the warehouse impressed narrow and less structured cause inefficiencies time retrieval and storage of materials, as well as complicate the operator in handling the placement process raw materials. In the method of shared storage and rail space (relationchip chart) for the relationship between activity is indicated by activity relationship approach, which shows each activity as a single activity model in the form of a diagram. ARD basic idea of the link between patterns of flow of goods and location of service activities related to production activities. ARD is the development of ARC (activity relationship chart).
\end{abstract}

Keywords : Warehouse shared storage, rel space

\section{PENDAhUluan}

System penyimpanan pada industri manufaktur di era moderen ini merupakan hal yang sangat penting peranannya apalagi perusahaan yang sekalanya internasional, PT XXXY ini merupakan salah satu perusahaan manufaktur pembuatan sepatu, tidak mungkin langsung memproduksi atau mendistribusikan kesemua unit kerja. hal ini menyebabkan kebutuhan adanya gudang raw material, sistem penyimpanan gudang tidak harus berukuran luas sebab jika ditunjang inventaris yang baik maka pemanfaatan gudang bisa maksimal permasalahan yang dihadapi oleh perusahaan terjadi di gudang bahan baku (raw material). kurang baiknya prosedur penataan barang pada gudang menimbulkan masalah pada gudang tersebut, sehingga gudang terkesan sempit dan kurang tertata menyebabkan ketidak efisienan waktu pengambilan dan penyimpanan material, serta menyulitkan operator dalam menangani proses penempatan raw material. Pada metode shared storage dan rel space (relationchip chart) ini untuk adalah hubungan antar aktivitas yang ditunjukkan dengan pendekatan keterkaitan kegiatan, yang menunjukkan setiap kegiatan sebagai satu model kegiatan tunggal ke dalam bentuk diagram. $A R D$ menjadi dasar perencanaan keterkaitan antara pola aliran barang dan lokasi kegiatan pelayanan yang berhubungan dengan kegiatan produksi. $A R D$ merupakan pengembangan dari ARC (activity relationship chart).

\section{DASAR TEORI}

\section{A. Perancangan Tata Letak}

Menurut Apple (1990) dalam Nurahmatullah (2011) gudang harus dirancang dengan memperhitungkan kecepatan gerak barang yang bergerak cepat lebih baik diletakkan dekat dengan tempat pengambilan barang, sehingga mengurangi seringnya gerakan bolak-balik. dalam gudang penyimpanan, faktor yang berpengaruh sangat besar terhadap penanganan barang ialah letak dan desain gedung di mana barang itu disimpan. pengaturan konfigurasi stasiun kerja produksi yang disusun berdasarkan interaksi antar departemen yang memenuhi kriteria-kriteria tertentu sehingga interaksi tersebut optimal dalam proses transformasi material dari bahan mentah menjadi produk jadi. perencanaan tata letak fasilitas gudang merupakan suatu persoalan yang penting, 
karena pabrik atau industri akan beroperasi dalam jangka waktu yang lama, maka kesalahan di dalam analisis dan perencanaan layout gudang dan suplay raw material akan menyebabkan kegiatan produksi berlangsung tidak efektif dan tidak efisien. setudi tentang pengaturan tata letak fasilitas selalu berkaitan dengan minimasi total cost.

\section{B. Pengaturan Tata Letak Gudang}

Pengaturan dalam tata letak raw material terutama menentukan jumlah lahan yang akan disimpan merupakan material setengah jadi atau bahan baku yang siap proses, dalam penentuan langkah tata letak sebuah gudang diperlukan beberapa langkah yaitu :

a. Memperhitungkan kapasitas area

b. Mengklasifikasi raw material berdasarkan dari custummer

c. Perhitungan kebutuhan area untuk masing-masing matrialnya

d. Penentuan tata letak dan moving untuk masing-masing area

(Chugito 2009).

Tata letak gudang merupakan desain yang mencoba berusaha meminimalkan total biaya dengan mencari pertukaran (trade-offs) antara luas ruangan dengan penanganan bahan.

\section{Pengolahan data dengan pendekatan shared storage}

Langkah-langkah pada pengolahan data dengan menggunakan pendekatan Shared storage

\section{Rectilinier Distance}

Jarak diukur sepanjang lintasan menggunakan garis tegak lurus (orthogonal) satu dengan yang lainnya sebagai contoh adalah material yang berpindah sepanjang gang aisle pada gudang terlihat pada gambar rumus Rectilinier Distance:

$\operatorname{dij}=(x a)^{2}+(y b)^{2}$.

(Ekoanindiyo, 2011)

\section{Euclidean Distance}

Jarak diukur sepanjang lintasan garis lurus antara dua buah titik jarak euclidean dapat diilustrasikan sebagai alat konveyor lurus yang memotong dua buah stasiun dan terlihat pada rumus gambar Euclidean Distance:

$\operatorname{dij}=\sqrt{ }\left[(x 2-x 1)^{2}+(y 2 y 1)^{2}\right]$

(Ekoanindiyo, 2012)

\section{Squared Euclidean Distance}

Jarak diukur sepanjang lintasan yang sebenarnya antara dua buah titik contoh padah alat atau kendaraan terkendali dalam perjalanannya harus mengikuti arah-arah yang sudah ditentukan pada jaringan lintasan yang sudah termendali, oleh karenanya jarak lintasan lebih panjang dibandingkan dengan kedua metode yang diatas dengan gambar rumus:

$\operatorname{dij}=(x-a)^{2}+(y-b)^{2}$

(Ekoanindiyo,2011)

\section{Penentuan lebar gang (aisle)}

Pemanfaatan ruang gang atau allowance untuk menggerakkan material handling menggunakan forklift sebagai alat angkut produknya. Aisle dimanfaatkan sebagai gang atau jalur material handling, gerakan perpindahan personil, adapun material handling 
yang digunakan adalah hand pallet. Jadi aisle yang dibutuhkan berdasarkan kebutuhan untuk jalur sesuai dengan ukuran dimensi hand pallet. penentuan luas gang yang diperlukan adalah berdasarkan dua kali dimensi terpanjang yaitu lebar hand pallet saat membawa produk.

Aisle space $=2 x$ lebar bahan yang melintas.

Aisle space $=2 \times 1 \mathrm{~m}=2 \mathrm{~m}$.

(Nurrahmatullah, 2011).

\section{E. Pendekatan Metode rel space (relationchip chart)}

Tahapan metode rel space (Ekoanindiyo, 2011) metode rel space ini adalah hubungan antar aktivitas yang ditunjukkan dengan pendekatan keterkaitan kegiatan, yang menunjukkan setiap kegiatan sebagai satu model kegiatan tunggal ke dalam bentuk diagram.

Langkah-langkanya meliputi:

(1). Menyusun preseden diagram sesuai dengan layout yang akan diperbaiki, dalam penyusunan ini hanya bagian yang mengalami proses flaw material yang berjalan. (2). Menentukan task time atau workstation cycle time $C=$ production time per day / customer demand (or output per day). (3). Menentukan secara teori jumlah dari permintaan workstasion. $N=$ total task time / takt time. (4). Menentukan aturan dari penugasan, sebagai contohnya aturan yang pertama adalah "number of following tasks" dan aturan kedua adalah "longest operation time" (5). Menugaskan tugas pada workstations mengikuti aturan penugasan dan sesuai dengan precedence dan cycle Time. (6). Menghitung efficiency= total task time / (actual number of workstations takt time)

Dalam penyusunan tabel $A R C$ akan memberikan pertimbangan mengenai derajat kedekatan dengan ukuran yang lebeih bersifat kualitatif seperti: mutlak atau tidak mutlak harus berdekatan, cukup penting untuk diletakkan berdekatan dan lainlain, maka dapat digambarkan simbol activity relationship chart dalam tabel 1.

Tabel 1. Simbol - Simbol activity relationship chart

\begin{tabular}{|c|c|c|c|}
\hline No. & Tingkat kepentingan & Kode & Simbol grafis \\
\hline 1 & MUTLAK PENTING & A & $\overline{\overline{ }}$ \\
\hline 2 & PENTING TERTENTU & E & $\overline{\overline{~ I}}$ \\
\hline 3. & PENTING & $\mathrm{O}$ & \\
\hline 4. & BIASA & $\mathrm{U}$ & None \\
\hline 5. & TIDAK PENTING & $\mathrm{X}$ & \\
\hline 6. & TIDAK DIINGINKAN & & \\
\hline
\end{tabular}

Sumber: (Wignjosoebroto, 2003)

\section{F. Pustaka Terdahulu}

Penelitihan terdahulu dilakukan oleh Nurahmatullah (2011), tentang tata letak sebuah gudang bahan baku serta dasar yang diperlukan dalam menentuan metode shared storage dan rel space dapat memberikan pemecahan bagaimana sebuah gudang bahan baku dapat terintegrasi dengan benar dari berbagai aspek layout maupun ruang gudang tersebut, gudang harus dirancang dengan memperhitungkan kecepatan gerak barang yang bergerak cepat lebih baik diletakkan dekat dengan tempat pengambilan barang, sehingga mengurangi seringnya gerakan bolak-balik. dalam gudang 
penyimpanan, faktor yang berpengaruh sangat besar terhadap penanganan barang ialah letak dan desain gedung dimana barang itu disimpan.

\section{G. Pengaturan Tata Letak Gudang}

Pengaturan dalam tata letak raw material terutama menentukan jumlahlahan yang akan disimpan merupakan material setengah jadi atau bahan baku yang siap proses, dalam penentuan langkah tata letak sebuah gudang diperlukan beberapa langkah yaitu :

a. Memperhitungkan kapasitas area

b. Mengklasifikasi raw material berdasarkan dari custummer

c. Perhitungan kebutuhan area untuk masing-masing matrialnya

d. Penentuan tata letak dan moving untuk masing-masing area

(Ekoanindiyo, 2012) gudang adalah suatu fungsi penyimpanan berbagai macam jenis produk yang memiliki unit penyimpanan dalam jumlah yang besar maupun yang kecil dalam jangkah waktu saat produk dihasilkan oleh pabrik penjual dan saat produk dibutuhkan oleh pelanggan atau stasiun kerja dalam fasilitas produksi. gudang sebagai tempat yang dibebani tugas untuk menyimpan barang yang akan dipergunakan dalam produksi, sampai barang tersebut diminta sesuai dengan jadwal produksi. 


\section{METODOLOGI}

\section{Diagram alir Pemecahan Masalah}

Diagram alir gambar 1 menjelaskan dan menerangkan alur dari sebuah penelitian agar dapat dipahami dari berbagai aspek permasalahan.

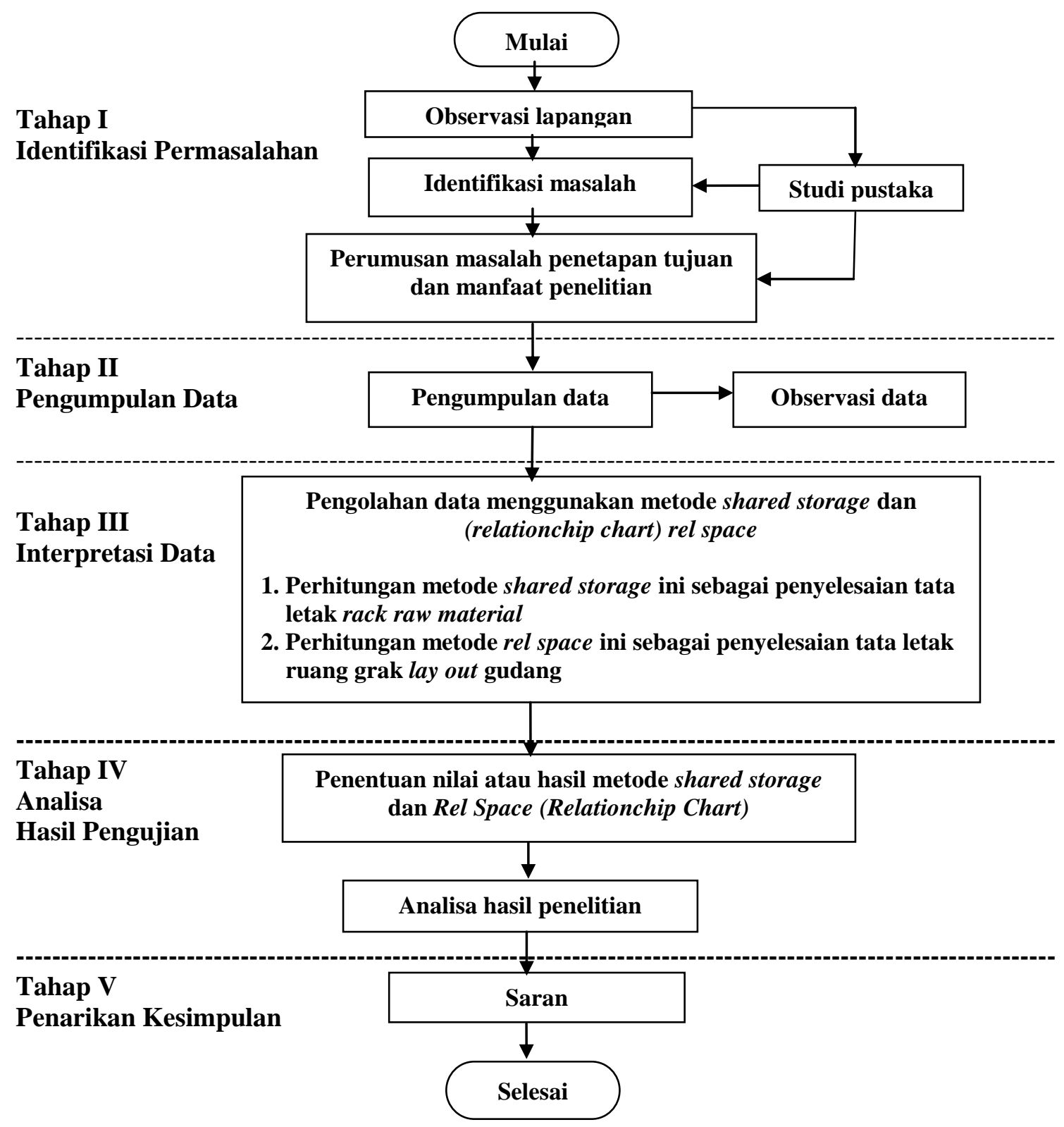

Gambar 1. Diagram alir penelitian 


\section{HASIL DAN PEMBAHASAN}

- Tahap identifikasi

- Interpretasi data

Hasil dari pengumpulan data di atas merupakan cara penentuan sebuah metode, selanjutnya dilakukan pengolahan data yaitu metode shared storage dan rel space.

\section{A. Perhitungan metode shared storage}

Perhitungan metode ini adalah di mana penempatan produk diatur secara berhatihati dengan mengetahui berapa lama waktu antara masing-masing pengiriman dari tiaptiap produk dan menggunakan slot pada tabel 2.

Tabel 2 jenis produk

\begin{tabular}{|l|l|c|}
\hline No & Jenis Produk & Waktu/ (hari) \\
\hline 1. & Produk colour kulit & 6 hari \\
\hline 2. & Produk lem & 7 hari \\
\hline 3. & Produk soul rubber & 7 hari \\
\hline 4. & Produk spray & 7 hari \\
\hline 5. & Produk semir & 7 hari \\
\hline
\end{tabular}

Dari data tabel 2 dapat ditentukan berapa banyak kebutuhan ruang untuk dengan cara mengalihkan kapasitas produksi (50 per hari) dengan lama pengiriman terbesar (7 hari) yaitu 350 produk di dalam gudang. Ukuran produk $1,5 \mathrm{~m} \mathrm{x} 1,5 \mathrm{~m}=1,725 \mathrm{~m}^{2}$, sehingga kebutuhan ruang untuk produk dengan lama pengiriman rata - rata adalah :

Kebutuhan ruang untuk ptoduk dalam 7 hari $=350 \times 1,725 \mathrm{~m}^{2}=603,75 \mathrm{~m}^{2}$

Kemudian kebutuhan ruang untuk pergerakan material handling (forklift) adalah dengan dimensi terpanjang dari forklift ketika membawa produk yaitu diagonalnya $(3,4 \mathrm{~m})$. maka dibutuhkan gang selebar $3,4 \mathrm{~m}$ untuk pergerakan forklift sehingga dapat menghasilkan ruang gerak saat pengambilan raw material.

Urutan dalam peletakan hasil produksi agar perpindahan dapat dilangsungkan dengan cepat diantaranya adalah:

1. Satu tempat terdiri dari 18 jenis produk (dua tingkat)

2. Hasil pertama kali datang diletakkan pada area terdekat dengan pintu masuk.

3. Dalam meletakkan produk dilarang meletakkan lebih dari 2 hasil produksi.

4. Dalam melakukan laporan gudang menggunakan kartu gudang sendiri.

Seperti jarak area yang terdekat ini menunjukan aktivitas penempatan raw material dan dapat dilihat pada tabel 3.

Tabel 3 jarak tempuh antara pintu ke area penyimpanan

\begin{tabular}{|l|l|l|}
\hline No & Area Penyimpanan & Jarak $(\mathrm{m})$ \\
\hline 1. & $1-1$ & 9.075 \\
\hline 2. & $1-2$ & 9.075 \\
\hline 3. & $1-3$ & 14.375 \\
\hline 4. & $1-4$ & 14.375 \\
\hline 5. & $2-1$ & 15.925 \\
\hline 6. & $2-2$ & 15.925 \\
\hline 7 & $2-3$ & 21.225 \\
\hline 8. & $2-4$ & 21.225 \\
\hline 9. & $3-1$ & 22.775 \\
\hline 10. & $3-2$ & 22.775 \\
\hline 11. & $3-3$ & 28.075 \\
\hline 12. & $3-4$ & 28.075 \\
\hline 13. & $4-1$ & 29.625 \\
\hline
\end{tabular}




\begin{tabular}{|l|l|l|}
\hline 14. & $4-2$ & 29.625 \\
\hline 15. & $4-3$ & 34.925 \\
\hline 16. & $4-4$ & 34.925 \\
\hline 17. & $5-1$ & 36.475 \\
\hline 18. & $5-2$ & 36.475 \\
\hline 19. & $5-3$ & 41.775 \\
\hline 20. & $5-4$ & 41.775 \\
\hline 21. & $6-1$ & 43.325 \\
\hline 22. & $6-2$ & 43.225 \\
\hline 23. & $6-3$ & 48.625 \\
\hline 24. & $6-4$ & 48.625 \\
\hline 25. & $7-1$ & 50.175 \\
\hline 26. & $7-2$ & 50.175 \\
\hline 27. & $7-3$ & 55.475 \\
\hline 28. & $7-4$ & 55.475 \\
\hline
\end{tabular}

Terdapat 28 tempat yang digunakan untuk meletakkan produk, rencana gudang yang digunakan mampu memuat 504 produk atau untuk 10 hari penyimpanan.

\section{Jarak tempuh forklift rata-rata dalam sebulan}

Perhitungan jarak tempuh forklift diuji pada periode ke 13, dimana periode ke 13 merupakan dari rata - rata, data permintaan konsumen pada tahun 2015 untuk masing masing produk, frekuensi permintaan rata - rata per bulan dan waktu waktu pengiriman, yang akhirnya diperoleh jarak tempuh dengan sebesar 56102,06 m.

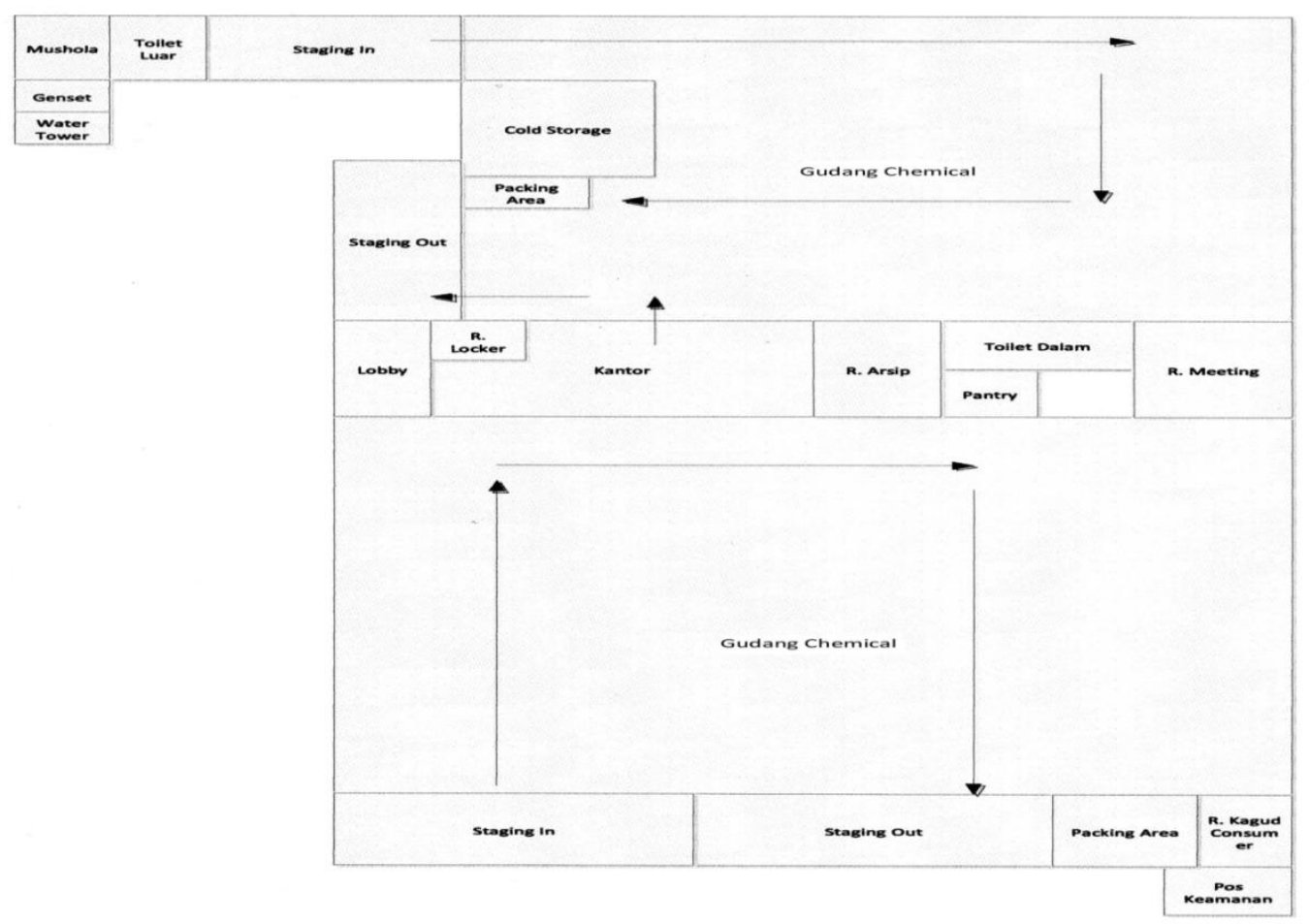

Gambar 2. Area lokasi keseluruan bentuk shared storage yang merupakan bentuk diagram distribusi center. 


\section{B. Perhitungan metode rel space}

Perhitungan rel space diperoleh dari aliran urutan kerja berdasarkan keterkaitan kegiatan dengan metode hubungan keterkaitan yang diberi kode garis diperoleh hasil paa gambar 3.

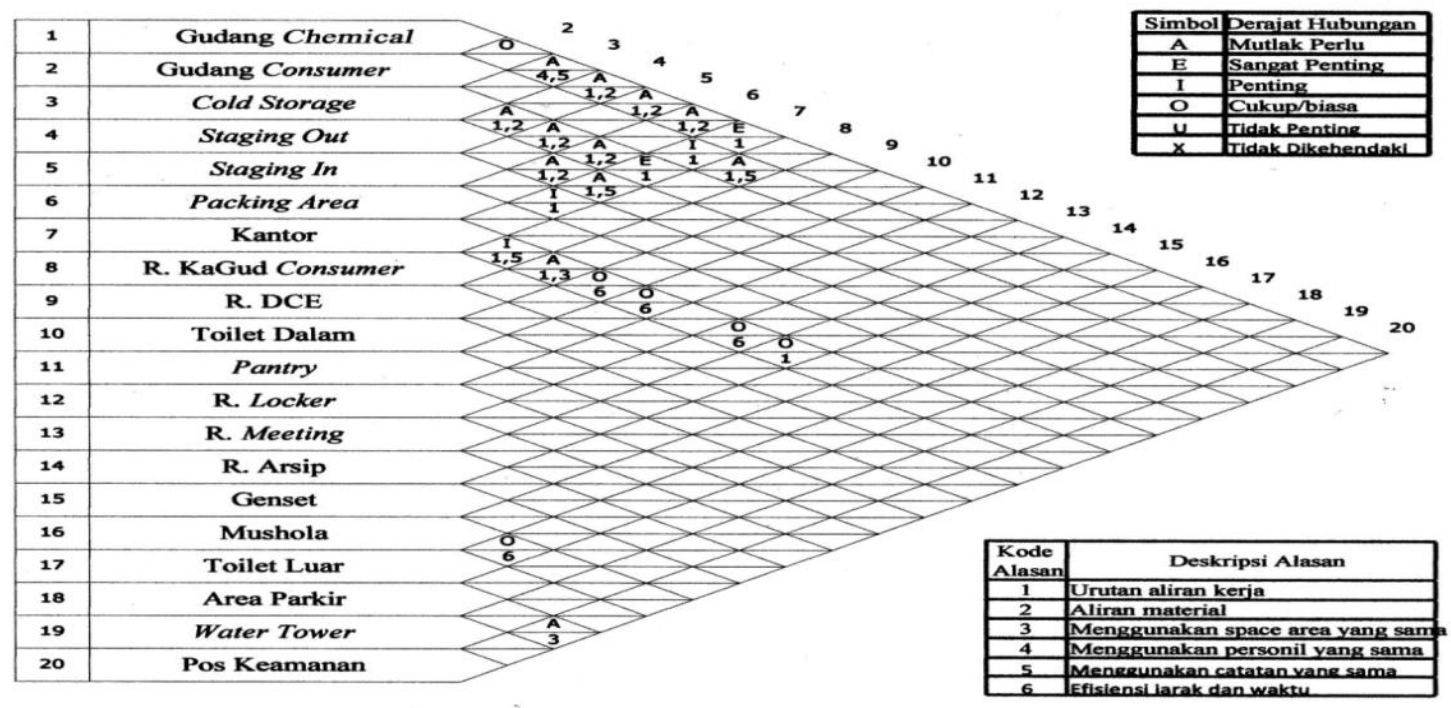

Gambar 3. Activity relationship chart

Gambar 4 adalah perancangan layout rel space yang berdasarkan pada susunan blok-blok diagram pada AAD dengan menyesuaikan benda-benda sesuai dengan skala.
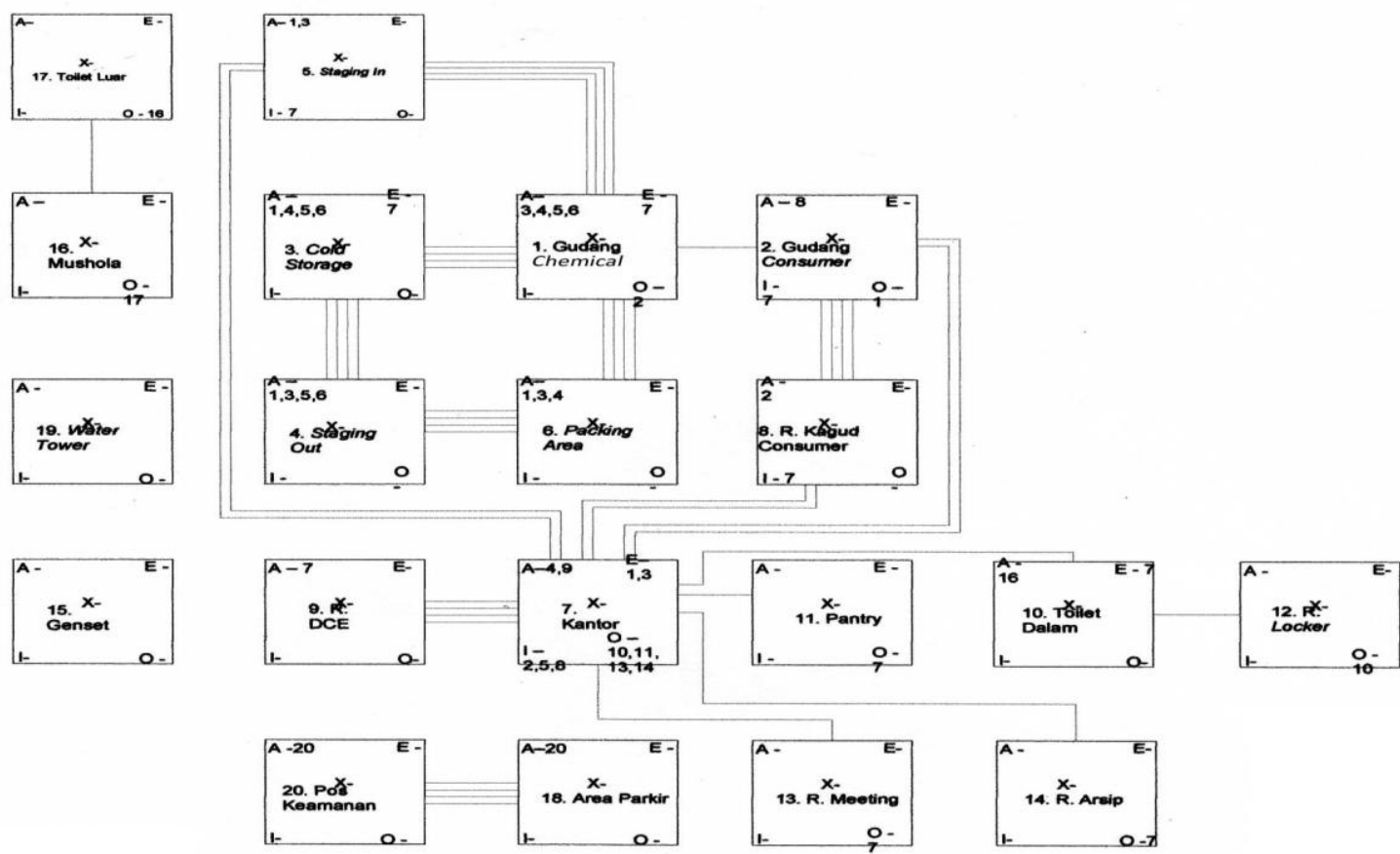

Gambar 4. perancangan layout rel space 


\section{Hasil layout shared storage}

Dari perhitungan yang diperoleh melalui metode shared storage dapat memperoleh layout tata letak gudang yang terintegrasi yaitu peletakan material kedalam rack dan dihitung pengelompokannya dengan block- blok, kartu gudang pada area terdekat pintu keluar. dan memperoleh hasil dengan sytem FIFO (firs in first out) maka finish hasil dari metode ini dapat terlihat pada gambar 5 layout penataan material kedalam rack yang sesuai.

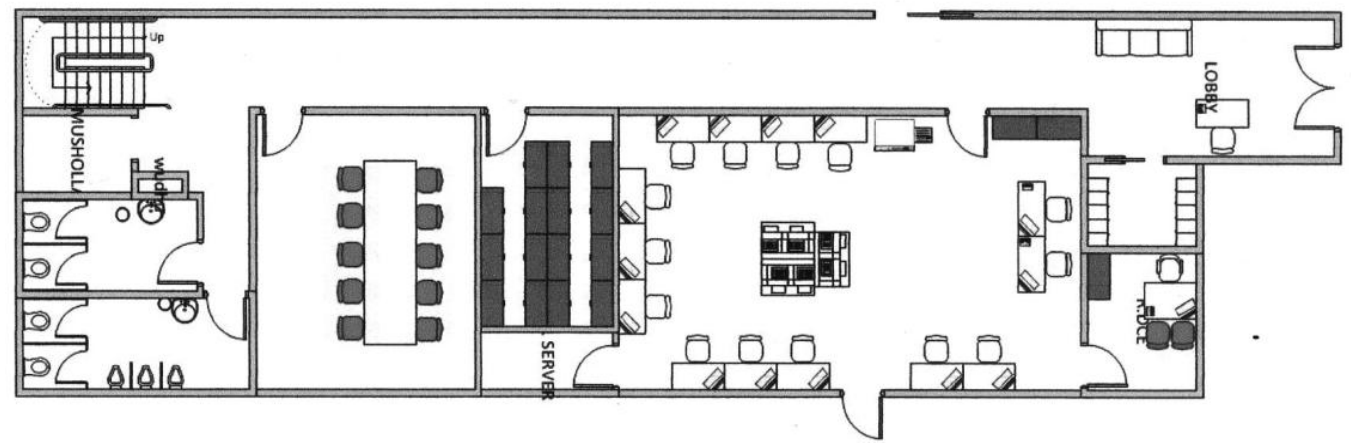

Gambar 5. Hasil layout shared storage

\section{Hasil layout rel space}

Dari perhitungan rel space diperoleh aliran urutan kerja berdasarkan keterkaitan kegiatan dengan metode hubungan keterkaitan yang diberi kode garis maka hasil finish dan dapat menentukan sebuah aliran tata letak gudang akan syarat aturan yang sitematis, efisinsi menghemat biaya tempat gudang itu sendiri. metode ini salah satu penyelesaian yang utama sebagai acuan sebuah penelitian ditunjukan gambar 6 keseluruan layout gudang raw material chemical.

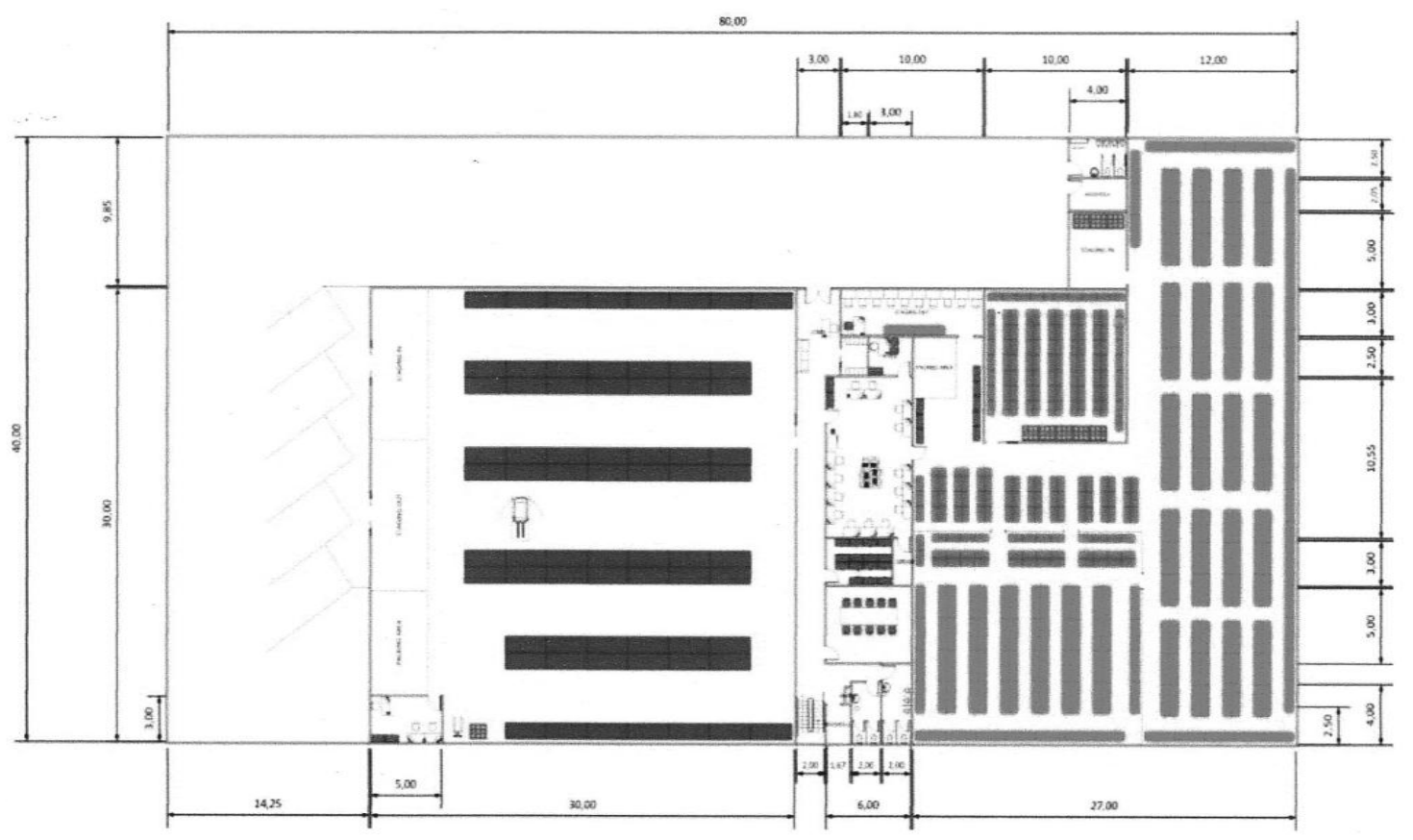

Gambar 6. Hasil layout rel space 


\section{KESIMPULAN}

Dalam metode shaared storage dan rel space ini dapat digunakan sebagai bahan pertimbangan dalam membuat tata letak gudang atau pabrik menjadi tempat yang efisien. Dan shared storage merupakan metode yang dapat digunakan untuk meletakkan raw material ditempat yang paling dekat dengan pintu keluar masuk. Begitu pula dengan metode rel space digunakan untuk merancang tata letak gudang yang efisien.

\section{DAFTAR PUSTAKA}

[1] Chugito William Jason (2009) - 1200950920. Evaluasi Sistem Pergudangan dan Pendistribusian Barang. Binus University, Jakarta

[2] Ekoanindiyo Firman Ardiansyah, Yaumal Agit Wedana. (2012) Perencanaan Tata Letak Gudang Menggunakan Metode Shared Storage. Jurnal Dinamika TeknikVol. VI, No. 1, Hal 46 - 57.

[3] Ekoanindiyo Firman Ardiansyah (2011). Perancangan Tata Letak Gudang Dengan Metode Shared Storage. Universitas stikubank semarang. Jurnal Dinamika TeknikVol. V. No. 2.Hal $64-74$.

[4] Nurrahmatullah, Sabaruddin Akhmad, Sugeng Purwoko. (2012). PerencanaanTata Letak Gudang Produk Jadi Pendekatan Shared Storage. Jurnal Program Studi Teknik Industri,Fakultas Teknik. Universitas Truno Joyo Madura Jl.Raya Talang Po Box 2 Kamal, Bangkalan.

[5] Wignjosoebroto, Sritomo(1996) perencnaan tata letak ruanglingkup pabrik dan pemindahan bahan, Pt.Gunawidya Jakarta. 